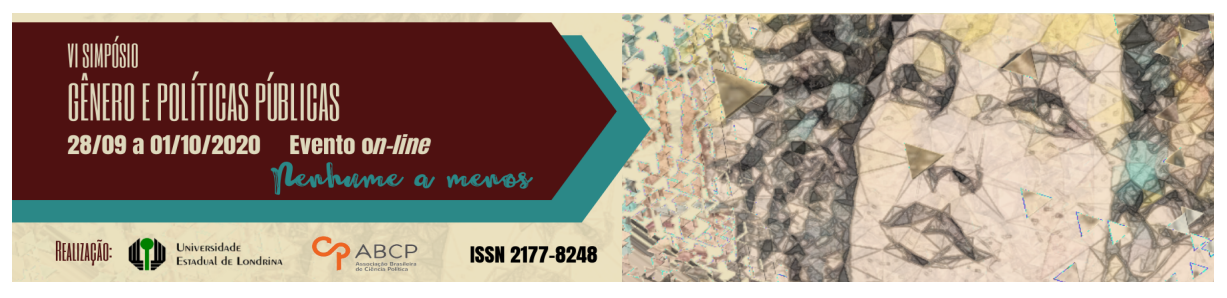

\title{
Das ruas ao parlamento: efeitos de sentido do "Ni Una Menos" no âmbito político
}

\author{
Anelise Gregis Estivalet ${ }^{1}$; Gabriel Dvoskin ${ }^{2}$
}

\section{Resumo}

As feministas foram precursoras em estratégias inovadoras, tais como o "efeito bumerangue", que mobiliza a opinião global dirigindo a atenção para denunciar abusos locais e para envergonhar os estados que simplesmente fecham os olhos para eles. O resultado foi uma nova forma promissora de ativismo feminista transnacional. Neste trabalho, nos propomos a analisar as repercussões obtidas no âmbito político, tanto na Argentina como no Brasil, tendo como base os signos que resultaram em movimentos feministas como o "Ni Una Menos". Especificamente, nos interessa indagar se as representações e discursos postos em circulação a nível social foram retomadas em projetos legislativos apresentados dentro das temáticas de gênero e sexualidade. A partir da análise dos debates pela legalização do aborto e em torno do feminicídio, observamos que se mantém uma distância significativa entre as representações que circulam sobre esses temas a nível social e aquelas produzidas no âmbito legislativo.

\footnotetext{
1 Bacharela e Licenciada em Ciências Sociais pela Universidade Federal do Rio Grande do Sul (UFRGS). Especialista em Estudos de Gênero pelo Conselho Latino-americano de Ciências Sociais (CLACSO). Mestra em Educação pela Universidade Federal Fluminense (UFF) e Doutora em Ciências Sociais pela Universidade do Vale do Rio dos Sinos (UNISINOS) tendo realizado estágio doutoral junto ao Laboratoire Éthique Médicale da Université Paris Descartes - Sorbonne (PARIS V) e Centre dÉtudes sur 1Actuel et le Quotidien (CEAQ-Sorbonne). Atualmente é professora na Faculdade de Educação da Universidade de Brasília (UNB). E-mail: anegregis@gmail.com.

2 Gabriel Dvoskin é doutor em Linguística pela Universidad de Buenos Aires (UBA) e licenciado em Letras pela mesma universidade. É docente da área de Letras (UBA) e ministra seminários sobre Análise de Discurso. É bolsista de Formação em Investigações Estratégicas (UBA) onde analisa as características do discurso pedagógico e questões de gênero e sexualidade na educação formal. E-mail: gabidvoskin@gmail.com.
}

GT 18 - Políticas públicas de gênero no Brasil do século XXI: avanços e desafios 
Palavras-chave: movimento feminista; ni una menos; agenda pública.

\title{
From the streets to the parliament: meaning effects of "Ni Una Menos" in the political sphere
}

\begin{abstract}
Feminists were pioneers in innovative strategies, such as the "boomerang effect", which mobilizes global opinion by directing attention to denouncing local abuses and to shaming states that simply turn a blind eye to them. The result was a promising new form of feminist, transnational. In this work, we propose to analyze the repercussions obtained in the political sphere, both in Argentina and in Brazil, based on the signs that resulted in feminist movements such as "Ni Una Menos". Specifically, we are interested in asking whether the representations and speeches put into circulation at the social level were taken up in legislative projects presented within the themes of gender and sexuality. From the analysis of the debates on the legalization of abortion and on feminicide, we observed that a significant distance is maintained between the representations that circulate on these topics at the social level and those produced in the legislative sphere.
\end{abstract}

Keywords: feminist movement; ni una menos; public agenda.

\section{Introdução}

Em 3 de junho de 2015 ocorreu, na Argentina, uma mobilização massiva contra a violência de gênero sob a consigna "Ni Una Menos", inspirada na frase "Ni una muerte más", escrita por Susana Chávez 3 em um de seus poemas como forma de protesto frente aos feminicidios. A marcha foi realizada em diferentes cidades da Argentina e teve como epicentro a Praça do Congresso da Nação, localizada na Cidade de Buenos Aires, onde se concentraram-se mais de 200 mil pessoas (HERNÁNDEZ et al, 2015).

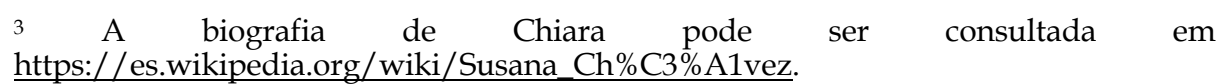


A convocatória foi difundida 23 dias antes através da rede social twitter por um coletivo heterogêneo, formado por jornalistas, artistas, acadêmicas e militantes de movimentos feministas, que se propuseram a trascender as lógicas partidárias a partir de uma mensagem clara e sensível, que permitiria alcançar a maior quantidade possível de pessoas. Essa chamada realizou-se em um contexto de numerosos casos de feminicidios ${ }^{4}$ ocorridos na Argentina5 ${ }^{5}$, entre eles o de Chiara Páez, ocorrido em 10 de maio de 2015. Chiara tinha 14 anos sendo, portanto, uma adolescente e o fator desencadeante do feminicídio foi sua gravidez (BIDASECA, 2015).

A multitude presente na marcha pôs em evidência o repúdio de uma grande parte da sociedade à violência machista. Essa concientização foi resultado de anos de militância dos movimentos feministas, na Argentina, que tem como um de seus impactos mais notórios os Encontros Nacionais de Mulheres, que são realizados anualmente desde 1987 e, na última década, tem ganhado relevância por sua luta pela difusão das atividades e discussões que ali se produzem (FELITTI; PRIETO, 2018). Já no caso do feminicidio, o ciclo da tipificação desse delito teve início em 2007, com a aprovação de leis em diversos países como Argentina, Bolívia, Chile, Colômbia, Costa Rica, El Salvador, Equador, Guatemala, Honduras, México, Nicarágua, Panamá, Peru, República Dominicana e Venezuela. No Brasil, a lei do feminicidio foi criada a partir de uma recomendação da Comissão Parlamentar Mista de Inquérito sobre Violência contra a Mulher (CPMI-VCM), que investigou a violência contra as mulheres nos estados brasileiros no período de março de 2012 a julho de 2013. Dados do Observatório de

\footnotetext{
4 Podemos definir o feminicidio como a última instância de controle da mulher pelo homem: o controle da vida e da morte. Ele se expressa como afirmação irrestrita de posse, igualando a mulher a um objeto, quando cometido por parceiro ou ex-parceiro; como subjugação da intimidade e da sexualidade da mulher, por meio da violência sexual associada ao assassinato; como destruição da identidade da mulher, pela mutilação ou desfiguração de seu corpo; como aviltamento da dignidade da mulher, submetendo-a a tortura ou a tratamento cruel ou degradante (CPMI-VCM, 2013).

${ }^{5}$ Em 2014, foram registrados aproximadamente 277 casos, sendo 1 a cada 31 horas, dos quais $80 \%$ tinham algum tipo de vinculo com o feminicida (Asociación Civil la Casa del Encuentro, 2014).
} 
Igualdade de Gênero da Comissão Econômica para a América Latina e Caribe (Cepal) registraram, em 2018, 1.206 casos de feminicidio, enquanto na Argentina foram registrados 255. Brasil e Argentina, ainda registraram taxas de 1.1 feminicídio para cada 100 mil habitantes.

Por outro lado, no caso da Argentina, essa sensibilização da sociedade em questões de gênero e sexualidade deve-se também à sanção de um conjunto de leis durante os governos kirchneristas ${ }^{6}$ (20032015) que visibilizaram temas que até esse momento estavam silenciados na esfera pública (TABBUSH et al, 2020). A Argentina, segundo dados da Organização das Nações Unidas (ONU), é o país da América Latina que apresenta uma das legislações mais completas da região. Podemos incluir nesse conjunto as leis de Educação Sexual Integral (2006), Proteção Integral das Mulheres (2009), Matrimônio Igualitário (2010), Identidade de Gênero (2012), Fertilização Assistida (2013) e Micaela (2019)7.

A grande repercussão que teve a marcha do Ni Una Menos impôs uma série de tópicos que não estavam presentes na agenda pública, na Argentina, especialmente aqueles relacionados com a violência machista, tanto em sua dimensão física e econômica como simbólica e também a outros vinculados com o prazer das práticas sexuais e com a libedade de decidir sobre seus próprios corpos e identidades ${ }^{8}$. A circulação de novos tópicos trouxe a utilização de novos signos como "dissidências sexuais", "feminicidio", "violência de gênero" ou "linguagem inclusiva", assim como pôs em cena as vozes de atores sociais que estavam ausentes à essa cojuntura ou cuja aparição estava restrita a espaços muito específicos.

Em efeito, adquiriram maior trascendência as referências dos movimentos feministas e acadêmicas com ampla trajetória no estudo

\footnotetext{
${ }^{6}$ Denominamos dessa maneira os governos de Néstor Kirchner (2003-2007) e de Cristina Fernández Kirchner (2007-2011 e 2011-2015).

7 Para uma caracterização detalhada dessas leis, consulte a página do Congresso da Nação Argentina: https:// www.congreso.gob.ar/leyes.php.

8 Tanto o manifesto quanto as reivindicações lidas na marcha podem ser consultadas em: http://niunamenos.org.ar/manifiestos/3-de-junio-2015/.
} 
desses temas. O campo das Ciências Sociais e Humanidades ousou inscrever no debate público, a partir da crítica ao paradigma biomédico "patriarcal" (MAFFIA, 2016), a historização das problemáticas de gênero (BARRANCOS, 2017; SEGATO, 2018) e o uso de uma linguagem não sexista (SARLO; KALINOWSKI, 2019). Nesse sentido, embora o eixo que desencadeou o movimento e a marcha fosse o feminicídio, o tratamento desses temas em novos espaços e por novas vozes, habilitou a circulação de representações que não só põem em foco o corpo da mulher como um objeto de cuidado, mas também o caráter emancipatório da mulher e de seu corpo (MORCILLO; FELITTI, 2017).

Assim, neste artigo, analisamos as repercussões obtidas no âmbito político, tanto na Argentina como no Brasil, utilizando-nos como base os signos que resultaram no movimento feminista "Ni Una Menos". Especificamente, nos interessa indagar se as representações e discursos postos em circulação a nível social foram retomadas em projetos legislativos apresentados dentro das temáticas de gênero e sexualidade. Para isso, analisamos os debates parlamentares da Interrupción Voluntaria del Embarazo (IVE), ocorridos na Argentina em 2018, e a lei do Feiminício (Lei 13.104/15), no caso do Brasil.

Abordamos o corpus com ferramentas da Análise de Discurso, campo interdisciplinar que constitui uma via de acesso para as análises sociais (DVOSKIN, 2019). A importância dos discursos nos processos de legitimação dos movimentos sociais, fenômenos culturais e projetos políticos faz desses um objeto privilegiado para analisar os conteúdos e representações que circulam na sociedade (ANGENOT, 2010).

\section{O debate sobre o aborto na Argentina}

Segundo estudo realizado por Silvia Mario e Edith Alejandra (2009), praticam-se, na Argentina, aproximadamente 450 mil abortos clandestinos por ano, constituindo a principal causa de mortalidade materna. Estima-se que desde a redemocratização, em 1983, tenham morrido em torno de 3.000 mulheres devido a abortos inseguros. 
Em 2018, se produziu um feito histórico na Argentina: pela primeira vez, colocou-se na pauta do Congresso da Nação o projeto de lei pela Interrupción Voluntaria del Embarazo (IVE)9. Embora o projeto tenha sido apresentado pela Campanha Nacional pelo Direito ao Aborto Legal, Seguro e Gratuito em sete oportunidades, nunca antes havia tido apoio suficiente dos legisladores para ser tratado no recinto parlamentário. Diferente dos anos anteriores, o projeto teve respaldo de 71 deputados e, posteriormente, foi posto em pauta pelo então presidente Mauricio Macri (2015-2019) - ainda que ele se pronunciasse explicitamente contra o projeto - permitindo que o debate pela legalização do aborto fosse incluído na agenda parlamentária desse ano.

Em 13 de junho de 2018, o projeto obteve aprovação na Câmara dos Deputados, com 129 votos a favor, 125 contra e uma abstenção. No entanto, quase dois meses após, em 8 de agosto, o projeto foi rejeitado pela Câmara de Senadores, com 38 votos contra, 31 a favor, duas abstenções e uma ausência.

Neste artigo, nos centramos, exclusivamente, em analisar o debate ocorrido na Câmara de Deputados, que iniciou-se na manhã de 13 de junho e terminou na manhã seguinte. Dado que, interessa-nos analisar as repercussões do movimento Ni Una Menos no âmbito político, decidimos focalizar nas intervenções dos deputados que se pronunciaram a favor do projeto, já que intuímos que ali apareceriam com maior preponderância as referências ao NUM, dado o posicionamento comum a favor da IVE. Por outro lado, dada a larga duração do debate, nossa análise esteve centrada, unicamente, nas intervenções dos deputados pertencentes aos dois principais blocos

\footnotetext{
9 Na Argentina, o Código Penal do ano de 1921 estabeleceu que somente em duas situações o aborto não era punível: quando a saúde da gestante está em risco ou se a gravidez provém de uma violação ou de um atentado ao pudor cometido contra uma mulher idiota ou demente (artículo 86). Embora essa lei ainda esteja em vigor, em 2015, incluiu-se a decisão da Corte Suprema de Justiça, de 2012, que declara que toda mulher que resulta grávida como produto de uma violação deve ter acesso a um aborto não punível sem necessidade de intervenção judicial.
} 
políticos desse momento em termos de representatividade: a Frente para la Victoria e o Pro.

Além do posicionamento a favor do projeto, nos interessa reconstruir as lógicas argumentativas (ANGENOT, 2015) sobre as quais se fundamentaram as posturas dos deputados, isso é, as premisas e as correntes discursivas a partir das quais concluíram seu voto a favor da IVE. Esse tipo de análise nos permite pôr em evidência os diferentes discursos que convivem na Argentina a favor da legalização do aborto e as representações produzidas sobre a mulher e seu corpo.

Podemos reconhecer três eixos principais que estruturam as argumentações dos deputados que se pronunciaram a favor da IVE, os quais aparecem na maioria das intervenções de modo conjunto, embora cada um deles habilite determinadas representações e correntes, assim como fecha outros. Esses eixos apresentam a legalização do aborto como: 1) assunto de saúde pública; 2) justiça social e, 3) direito da mulher a decidir sobre seu próprio corpo.

Ao longo do debate, observamos que o eixo que aparece de modo preponderante é a apresentação da legalização do aborto como um assunto de saúde pública:

No sólo yo, el diputado Lipovetzky, sostengo que este es un tema de salud pública ${ }^{10}$, sino que también lo dijeron tres ministros de salud de dos gobiernos distintos. [...] La legalización del aborto mejora la calidad de vida de las mujeres argentinas ${ }^{11}$ (DL: 39$40)$.

No exemplo, vemos, por um lado, que a associação do aborto com a saúde apresenta a problemática como um assunto técnico, que faz aparecer a figura do especialista como argumento de autoridade, neste

\footnotetext{
10 Tanto aqui como quando aparecem, as marcas em negrito são nossas.

11 Todos os exemplos foram extraídos do Diario de Sesiones de la Cámara de Diputados de la Nación, $8^{\mathrm{a}}$ reunião $\quad 7^{\mathrm{a}}$ sessão ordinária. Disponível em https://www.diputados.gov.ar/secparl/dtaqui/diario_sesiones/index.html.

Doravante, será posto entre parênteses as iniciais do deputado responsável pela intervenção e o número da página.
} 
caso, o ministro da saúde. Por outro lado, esse eixo se fundamenta na ideia de saúde como ausência de enfermidade, característica do paradigma biomédico (DÍAZ, 1993). O aborto resulta, desse modo, associado ao risco, e sua legalização reverteria essa situação:

Es nuestro deber como diputados legislar para toda la sociedad y sobre todo para proteger a los sectores más vulnerables, como las numerosas mujeres que ponen en riesgo su vida o su salud para practicarse un aborto en absoluta clandestinidad (SMCA: 114).

Essa concepção de saúde - e do aborto - apresenta a mulher como um sujeito que deve se "proteger", como se observa no segundo exemplo. Essa passividade em sua condição de paciente, entretanto, contrasta com o papel ativo que se outorga em relação ao processo de abortar: seja através da forma reflexiva, tal como aparece no exemplo anterior, no qual a mesma mulher é a agente e a paciente do processo; ou quando se apresenta como um processo que exige um único participante que realiza a ação de maneira consciente e voluntária, a mulher enquanto ator social que desempenha esses papéis:

En la televisión no salen las mujeres pobres que abortan (PC: 116).

Nos últimos dois discursos, aparece um único ator implicado no processo de abortar: a mulher. Dessa maneira, se apresenta como uma prática individual, cuja responsabilidade recai exclusivamente sobre a mulher. Essa representação elide, por um lado, a quem realiza o procedimento cirúrgico e, por outro, aos responsáveis pelo aborto, que é ilegal na Argentina, condição essa que gera sua prática clandestina e trás risco, segundo essa lógica argumentativa. Em consequência, se omite quem são os culpados de produzir as mortes das mulheres submetidas ao aborto clandestino:

La clandestinidad y la desinformación ponen en riesgo la vida de las mujeres (SMCA: 115).

Las mujeres pobres que mueren por causa de un aborto (SMCA: 116). 
O uso de nominações (HODGE; KRESS, 1993), como "clandestinidad" e "desinformación", ou de processos que exigem um único participante experimentador, como "mueren", evitam a menção dos responsáveis da situação atual, fato que deixa sem explicitar o caráter ilegal do aborto, decisão essa que é política. Essa lógica argumentativa mantém uma valorização negativa do signo "aborto" ao concebê-lo como uma prática inerentemente indesejável, que põe em risco a vida da mulher, já que parte do pressuposto de que constitui-se enquanto uma medida de urgência, que se realiza unicamente quando outras formas preventivas fracassaram, como vemos no exemplo a seguir:

Empecemos por donde estamos de acuerdo: el aborto es una tragedia (FI: 142).

O segundo eixo que aparece com maior preponderância é o do direito da mulher a decidir sobre seu próprio corpo:

Hoy proclamamos que la ciudadanía de las mujeres tiene su mayor expresión en la libertad y autonomía sobre nuestros cuerpos, que son territorio personal y privado sobre el cual debemos tener la capacidad de decidir soberanamente, libres de coacción, de control o de violencia (C: 140).

Diferente do eixo anterior, que apresentaba o aborto como uma questão de saúde pública e, portanto, outorgava ao Estado um papel de protagonista, nesse último discurso, aparece a ideia do corpo como domínio privado e individual. A prática do aborto se apresenta, assim, como uma decisão pessoal e como tal, não deveria requerer outro argumento que a justifique além da vontade individual:

¿De qué pluralismo, de qué libertad individual, de qué república y de qué liberalismo estamos hablando si unos pretenden prevalecer con su pensamiento sobre otros? ¿De qué estamos hablando si obligamos a una mujer que no quiere continuar con su embarazo a elegir entre seguir forzosamente con él o la cárcel? (C: 140). 
A concepção do aborto como uma decisão pessoal incluiria sua prática como uma possibilidade além da vida sexual da mulher. Isso implicaría na remoção da valoração inerentemente negativa ao incluirlo em uma matriz simbólica diferente:

El aborto no es traumático por la práctica en sí, sino por la clandestinidad, por lo que significa tener que ocultarlo por la vergüenza a la que nos condenan y por el juicio moral que se ejerce sobre nosotras cuando decidimos sobre nuestro cuerpo en el marco de un sistema cultural patriarcal y heteronormativo que nos condiciona (E: 172).

Desde essa perspectiva, a legalização do aborto não seria eminentemente um assunto de saúde pública, o que constituiría, fundamentalmente, uma mudança de paradigma cultural, no qual o movimento de mulheres adquire um papel protagonista:

Buenas noches o buenos días a "todes"12. Es un día que está comenzando, que está despertando y continúa con una batalla cultural, iniciada por un movimiento revolucionario, como es el feminismo (C: 220).

De acordo com esse eixo, o problema já não é o aborto em si mesmo, mas o "aborto clandestino", signo que se opõe a outros signos como "aborto legal" ou "aborto voluntario":

La diferencia entre el aborto voluntario y el involuntario es el deseo (C: 150).

Nesse último trecho, o aborto aparece associado com o desejo, característica que lhe outorga uma valoração positiva. Assim como a maternidade, se apresenta como uma escolha da mulher, produto de uma decisão tomada de forma consciente e voluntária. Nesse sentido, a legalização do aborto constituiria uma ampliação dos direitos da mulher e contribuiria com a igualdade social, elemento que introduz o

12 A substituição do morfema masculino ou feminino pelo " $\mathrm{e}$ " responde ao uso da linguagem não binária, impulsionada em grande medida pelos movimentos feministas. 
terceiro eixo, a partir do qual se fundamenta o posicionamento a favor da IVE, da justiça social:

Distintas generaciones, abuelas, madres y compañeras están haciendo oír el grito de que quieren una verdadera justicia social, libertad e igualdad para poder decidir y disfrutar libremente de su cuerpo, de su sensualidad y poder tener una planificación sexual responsable (MC: 221).

As mulheres, no plural, não aparecem somente como protagonistas dessa mudança cultural, mas também como vozes legitimadas para pronunciarem-se sobre esses temas, vozes sobre as quais se respaldam os deputados no recinto parlamentar para fundamentar suas posturas. Nesse trecho, podemos notar que esse protagonismo se manifesta de modo ativo não só com "grito", como também em "decidir" e "disfrutar" de seu corpo. A ideia de justiça social como fundamento para a legalização do aborto conecta os três eixos mencionados. O Estado aparece, assim, como garantidor para que a mulher tome suas decisões sobre seu próprio corpo:

Avanzar con este proyecto es lograr construir una mejor comunidad, donde la libertad, la igualdad y la búsqueda de la justicia social van a ser una tarea de "todes". Por supuesto, en esa tarea de "todes" está la responsabilidad del Estado, de la planificación familiar de cada uno de los proyectos de vida de hombres y mujeres, de mujeres gestantes, de poder llevar adelante, en el momento que quieran, la planificación de su familia con educación sexual y teniendo a disposición todos los medios para llevar adelante la salud reproductiva como lo dispongan. [...] Además de la batalla cultural estaríamos avanzando en dar la posibilidad a la mujer y a la mujer gestante que quiera practicar -dentro de la reglamentación que tenga la ley, con la libertad debida y los lugares adecuados- la interrupción voluntaria de su embarazo si no fue planificado o deseado (MC: 220). 
Vemos, dessa maneira, como cada um dos eixos habilita determinadas representações sobre o aborto, a mulher e seu corpo. Como assinala Tabbush et al (2020), a apresentação dessa problemática desde um enfoque sanitarista, usualmente, pode constituir um caminho mais direto e imediato para alcançar sua sanção, liberando-a da batalha cultural necessária para instalar uma nova cosmovisão sobre o tema, o que poderia constituir a razão pela qual elegeu-se esse eixo no discurso dos deputados que se pronunciaram a favor do projeto de IVE. A inscrição do tema no campo dos direitos humanos articula a perspectiva individual da problemática, ligada ao paradigma neoliberal, concebendo-o como assunto de saúde pública.

Chama-nos a atenção que essa confluência dos três eixos pode ser observada de maneira preponderante tanto nos discursos dos deputados da Frente para la Victoria como do Pro. Por outro lado, embora só nas intervenções dos legisladores do Pro apareça de maneira recorrente o agradecimento ao então presidente Macri por ter habilitado a discussão do projeto no Congresso, ambas correntes fazem referência aos movimentos feministas, especialmente ao Ni Una Menos, como o principal responsável pela inclusão da legalização do aborto na agenda parlamentar:

Hace tres años algo cambió para siempre. El 3 de junio en la Argentina una inmensa marea de mujeres, al grito de "Ni una menos", se puso al frente de construir una sociedad y una nueva democracia. El debate que hoy tenemos acá es parte de esa pelea que están dando las mujeres en la calle (LG: 104).

A menção desses movimentos sociais durante o debate dá conta de sua trascendência no âmbito político tanto como ator protagonista como pela legitimação de sua voz para tratar questões de gênero e sexualidade. Ainda que o projeto não tenha sido aprovado no parlamento, o tema do aborto e outros tópicos semelhantes (como a violência de gênero e a educação sexual), adquiriram uma notoriedade na sociedade que nunca antes haviam tido na Argentina, dando conta de que se trata de um processo social em marcha. 


\section{O debate sobre o feminicídio no Brasil}

Desde 2006, os parâmetros que definem a violência doméstica contra a mulher, haviam sido estabelecidos pela Lei Maria da Penha ${ }^{13}$. No entanto, mesmo após 5 anos de sua existência, os números de atos violentos contra as mulheres não diminuíram e, ao contrário, aumentaram. Para tanto, em 2011, foi aprovado no Congresso Nacional o Requerimento $\mathrm{n}^{\mathrm{o}} 4$, que criou a Comissão Parlamentar Mista de Inquérito da Violência contra a Mulher14 (CPMIVCM), culminando, em 2015, com a aprovação da lei do feminicício (Lei no 13.104). A referida lei alterou o art. 121 do Código Penal (Decreto-Lei $n^{\circ} 2.848 / 1940$ ), definindo o feminicídio como um crime de homicídio hediondo (Lei $\mathrm{n}^{\mathrm{o}}$ 8.072/1990), tal qual como os crimes de estupro, genocídio e latrocínio. A pena prevista foi definida em reclusão de 12 a 30 anos.

O estudo realizado pela Comissão se baseou, principalmente, na existência de recomendações internacionais para a sua tipificação, como as inscritas no Relatório sobre Violência contra Mulheres, suas Causas e Consequências, assinado por Rashida Manjoo15, assim como nas Conclusões Acordadas na Comissão sobre o Status da Mulher, em sua

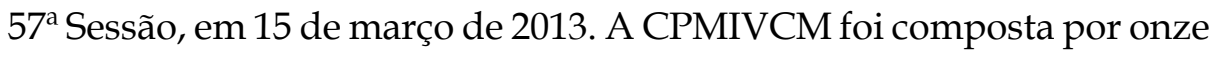
Senadores, onze Deputados Federais e igual número de suplentes, totalizando 33 congressistas. Foi assim composta por 8 senadoras - 3 do Partido dos Trabalhadores (PT), 1 do Partido Comunista do Brasil (PCdoB), 1 do Partido do Movimento Democrático Brasileiro (PMDB), 1

\footnotetext{
13 A lei Maria da Penha define a violencia doméstica como qualquer ação ou omissão baseada no gênero que lhe cause morte, lesão, sofrimento físico, sexual ou psicológico e dano moral ou patrimonial, no âmbito da unidade doméstica, da família ou em qualquer relação íntima de afeto, independentemente de orientação sexual.

14 A Comissão foi instituída com a finalidade de, no prazo de 180 (cento e oitenta) dias, investigar a situação da violência contra a mulher no Brasil e apurar denúncias de omissão por parte do poder público com relação à aplicação de instrumentos instituídos em lei para proteger as mulheres em situação de violência. Foram visitados dezessete estados brasileiros e o Distrito Federal. A Comissão teve como presidenta a Deputada Federal Jô Moraes (PCdoB/MG) e como relatora a Senadora Ana Rita (PT/ES).

15 UN General Assembly. A/HRC/20/16/Add.4. Human Rights Council. Twentieth session, May, 2012.
} 
do Partido Socialista Brasileiro (PSB), 1 do Partido da Social Democracia Brasileira (PSDB) e 1 do Democratas (DEM) e, 3 senadores (1 do PT, 1 do Partido Trabalhista Brasileiro (PTB) e 1 do (DEM); 21 deputadas federais - 3 do PT, 3 do PMDB, 3 do PSB, 2 do Partido Democrático Trabalhista (PDT), 2 do Partido Progressista (PP), 2 do DEM, 1 do Partido Popular Socialista (atual Cidadania), 1 do PTB, 1 do Partido da República (atual Partido Liberal-PL), 1 do Partido Verde (PV), 1 do Partido Trabalhista do Brasil (atual Avante) e 1 do PCdoB e, 3 deputados federais (1 do PT, 1 do PSDB e 1 do PP).

Segundo o Relatório Final da Comissão:

A CPMIVCM reuniu-se 37 vezes, por meio de 24 audiências públicas e 7 sessões deliberativas, sem contar as reuniões administrativas preparatórias. Nas sessões deliberativas, apreciou 744 requerimentos, aprovando 717 deles. Nas audiências públicas (dezoito das quais realizadas fora de Brasília, quando das visitas aos estados), ouviu especialistas no tema, representantes de organizações da sociedade civil, a Ministra da Secretaria de Políticas para as Mulheres, Eleonora Menicucci, e a Secretária Nacional de Enfrentamento à Violência contra Mulheres, Aparecida Gonçalves, além de outras autoridades do governo federal. Inquiriu, ainda, os titulares ou representantes das pastas estaduais responsáveis pelas questões de segurança pública, justiça e cidadania, saúde, políticas públicas para mulheres, assistência e desenvolvimento social, afora os titulares ou representantes do Poder Judiciário, do Ministério Público e das Defensorias Públicas dos estados (CPMIVCM, 2013, p. 11).

O tema da violência contra as mulheres está presente nos debates do Congresso Nacional desde o início dos anos 1990. Em 1992, foi instalada a Comissão Parlamentar de Inquérito (CPI) que investigou a questão da violência contra a mulher e foi presidida pela Deputada Federal Sandra Starling (PT), tendo como relatora a também Deputada Federal Etevalda Grassi de Menezes (PMDB) e concluiu que havia uma 
carência gritante na produção de dados, revelando o descaso por parte do Estado brasileiro com relação à temática da violência contra a mulher. A CPMI apontou, ainda, dados alarmantes nos números de homicídios. Em 2003, a CPMI da exploração sexual contra crianças e adolescentes, presidida pela Senadora Patrícia Saboya (PDT), tendo como Relatora a deputada federal Maria do Rosário (PT), apontou a grave violação dos direitos humanos das meninas e adolescentes submetidas à exploração sexual. Por fim, em 2013, a CPI do Tráfico de Pessoas, instalada pelo Senado Federal (presidida pela Senadora Vanessa Grazziontin, do PCdoB, e tendo como relatora a senadora Lítice da Mata, do PSB) destacou a necessidade de mudanças na legislação buscando a proteção das mulheres do tráfico e punindo os aliciadores e traficantes de mulheres (CPMIVCM, 2013).

O Projeto de Lei (PL) n ${ }^{o} 8305^{16}$, de autoria da CPMIVCM, foi apresentado pelo Senado Federal à Câmara dos Deputados, em regime de tramitação especial, em 17 de dezembro de 2014. Em 24 de fevereiro de 2015, os líderes do Partido Republicano da Ordem Social (PROS), Partido Republicano Brasileiro (atual Republicanos), Partido Trabalhista Nacional (atual Podemos), Partido da Mobilização Nacional, Partido Republicano Progressista (PRP), Partido Social Democrata Cristão (atual Democracia Cristã), Partido Renovador Trabalhista Brasileiro (PRTB), PT, PTB, PSDB, PPS, Partido Social Cristão (PSC), PDT, PSB e Partido Socialismo e Liberdade (PSOL), requereram que o PL passasse a tramitar em regime de urgência. Em 03 de março de 2015, a matéria foi discutida no plenário pela deputada Maria do Rosário e pelos deputados Evandro Gussi (PV-SP) e Edmilson Rodrigues (PSOL-PA). A discussão ocorreu em turno único e o PL foi aprovado por unanimidade nesse mesmo dia, sendo que a sessão na

16 Altera o art. 121 do Decreto-Lei n ${ }^{\circ}$ 2.848, de 7 de dezembro de 1940 (Código Penal), para prever o feminicídio como circunstância qualificadora do crime de homicídio, e o art. $1^{\circ}$ da Lei $\mathrm{n}^{\circ} 8.072$, de 25 de julho de 1990, para incluir o feminicídio no rol dos crimes hediondos. 
qual foi aprovado teve a participação de 471 parlamentares de um total de 513 deputados.

A votação iniciada na tarde do dia 03 de março de 2015 contou, primeiramente, com um pronunciamento da oradora, deputada Maria do Rosário (PT), no qual a mesma destacou a proximidade com o dia 08 de março, fazendo alusão aos 20 anos da IV Conferência Mundial da Mulher, à Lei Maria da Penha, às desigualdades existentes entre homens e mulheres nas diversas esferas, finalizando com uma homenagem à duas precursoras do feminismo no Brasil: Nísia Floresta e Bertha Lutz.

Cabe ressaltar que, após o pronunciamento da oradora, outros assuntos foram tratados na sessão. Chamamos a atenção para a fala do deputado Misael Varella, do DEM, que criticava o Estatuto do Desarmamento:

Quando mudaremos esse malfadado Estatuto do Desarmamento, que deixa os homens à mercê dos bandidos, sem o direito de legítima defesa? (Diário da Câmara dos Deputados, p.35).

Aqui, é preciso lembrar que a maior parte dos feminicidios ocorrem com o uso de arma de fogo. Ainda, na mesma sessão, foi apresentado pelo deputado Ronaldo Martins (PRB), o PL n 231 que dispõe sobre a dedução no Imposto de Renda Pessoa Física (IRPF) para despesas com segurança privada (incluindo aquisição de armas de fogo).

Posteriormente, a deputada Erika Kokay (PT), chamou atenção, novamente, para a pauta do feminicídio citando uma fala de Simone de Beauvoir. O deputado Edmilson Rodrigues (PSOL) retomou a discussão criticando uma fala anterior de que não deveria haver diferença no trato de autores de crimes de homicídio contra homens e mulheres. Ao final, o deputado Eduardo Cunha, que presidia a sessão, encerrou a discussão e pôs o PL em votação:

Todos abriram mão da orientação. No painel todos votam "sim", para registrar o apoio de todos os partidos às mulheres (...) Os Srs. Deputados que o 
aprovam permaneçam como se encontram. Aprovada (Diário da Câmara dos Deputados, p. 130).

A partir da análise dos discursos proferidos na sessão de discussão da lei do feminicídio tem-se uma breve certeza de que havia uma uniformidade pela aprovação do referido projeto. No entanto, uma análise mais aprofundada identificou contrariedades e fomentou a percepção do avanço de outras pautas conservadoras relacionadas ao armamento e a um entendimento de que mulheres e homens convivem em uma sociedade com igualdade de condições, pautas essas que negligenciam outras desigualdades inerentes à condição das mulheres brasileiras e latino-americanas.

\section{Conclusões}

As discussões teóricas sobre estudos de gênero e o tratamento das problemáticas em torno dessas questões têm ganhado grande relevância na América Latina nas últimas décadas, tanto no âmbito acadêmico quanto no social e político. As atividades impulsionadas em cada um desses espaços permitiram que fossem visibilizadas muitas problemáticas que anteriormente estavam silenciadas, seja porque haviam sido naturalizadas como práticas legítimas, seja porque sua circulação estava sumamente restringida.

Nesse artigo, abordamos as relações existentes entre a agenda pública e a agenda política, e nos centramos na análise dos efeitos de sentido que culminaram em movimentos como o Ni Una Menos, que teve seu ápice na realização da marcha de junho de 2015, assim como nas políticas resultantes na Argentina e no Brasil.

A partir da análise dos debates pela legalização do aborto e em torno do feminicídio, observamos que se mantém uma distância significativa entre as representações que circulam sobre esses temas a nível social e aquelas produzidas no âmbito legislativo. Fundamentalmente, notamos que as mudanças promovidas na esfera política se limitam a apresentar essas questões como problemas técnicos 
vinculados a assuntos de saúde pública. Em consequência, deixa-se de lado a discussão dos valores sociais e culturais hegemônicos, fato que impede que se ponha em questão a matriz simbólica que naturaliza e legitima essas práticas que põem em risco a vida das mulheres. Dessa maneira, as medidas que tem maior possibilidade de serem aprovadas são aquelas acompanhadas por discursos que reforçam o discurso patriarcal dominante; isto é, que se alinham por detrás dele ou não se oponhem, não questionam o eixo de referências imperante, falhando em constituir-se como um discurso emergente. A transformação cultural fica, assim, a cargo dos movimentos sociais, porém resulta silenciada no âmbito político (inclusive, em muitas ocasiões, ocasiona que medidas já sancionadas não possam ser implementadas).

Por fim, constatamos que somente a variável de gênero resulta insuficiente para abordar essas questões, já que é necessário considerar que outros fatores (de classe, etnia, regionais) operam na submissão e dominação dos corpos das mulheres. Assim, torna-se imprescindível contar com dados atualizados e estatísticas confiáveis que permitam cruzar as diferentes variáveis que atravessam as problemáticas de gênero. Do contrário, corre-se o risco de que as reivindicações de gênero sejam apropriadas pelos discursos neoliberais, que, ao invés de combater as desigualdades, as aprofundam.

\section{Referências}

ANGENOT, Marc. El discurso social: Los límites históricos de lo pensable y lo decible. Buenos Aires: Siglo XXI Editores, 2010.

BARRANCOS, Dora. Feminismos y agencias de las sexualidades disidentes. FAUR, Eleonor (comp.). Mujeres y varones en la Argentina de hoy: Géneros en movimiento. Buenos Aires: Siglo XXI, 2017.

BIDASECA, Karina. \#NiUnaMenos. Vivxs nos queremos. Buenos Aires: Milena Caserola, 2015.

BRASIL. Lei $n^{0} 11.340$, de 07 de agosto de 2006. Cria mecanismos para coibir a violência doméstica e familiar contra a mulher. 
BRASIL. Senado Federal. Relatório Final. Comissão Parlamentar Mista de Inquérito com a finalidade de investigar a situação da violência contra a mulher no Brasil e apurar denúncias de omissão por parte do poder público com relação à aplicação de instrumentos instituídos em lei para proteger as mulheres em situação de violência. Brasília, 2013.

BRASIL. Diário da Câmara dos Deputados. Ano LXX, nº 029, quarta-feira, 04 de março de 2015.

BRASIL. Diretrizes Nacionais do Feminicídio. Investigar, procesar e julgar com perspectiva de gênero as mortes violentas de mulheres. BrasíliaDF, 2016.

CARDOSO, Bruno Baptista; VIEIRA, Fernanda Morena dos Santos Barbeiro; SARACENI, Valeria. Aborto no Brasil: o que dizem os dados oficiais? Cad. Saúde Pública, Rio de Janeiro, v. 36, supl. 1, e00188718, 2020.

DÍAZ, Esther. La sexualidad y el poder. Buenos Aires: Almagesto, 1993.

DVOSKIN, Gabriel. Metodología cualitativa en el campo del Análisis del Discurso. In: AGUIRRE-AMENDÁRIZ, Elizabeth; JOHNSON MARDONES, Daniel. (Org.). Investigación Cualitativa en Latinoamérica. Santiago de Chile: Escaparta Ediciones, 2019.

FELITTI, Karina; PRIETO, María Sol. Configuraciones de la laicidad en los debates por la legalización del aborto en la Argentina: discursos parlamentarios y feministas (2015-2018). Salud colectiva, n. 14, v. 3, p. 405-423, 2018.

FELITTI, Karina; MORCILLO, Santiago. "Mi cuerpo es mío". Debates y disputas de los feminismos argentinos en torno al aborto y al sexo comercial. Amerika, 2017.

FERNANDÉZ, Mariana; LÓPEZ, Cecilia; Antonela PREZIO (2015). Un estudio de opinión pública: marcha Ni Una Menos. Argentina: Universidad de Buenos Aires.

FRASER, Nancy. O feminismo, o capitalismo e a astúcia da história. Mediações, Londrina, v. 14, n. 2, p. 11-33, jul./dez. 2009.

HODGE, Robert; KRESS, Günther. Lenguaje como Ideología. Londres: Routledge, 1993. 
KALINOWSKI, Santiago; SARLO, Beatriz. La lengua en disputa. Un debate sobre el lenguaje inclusivo. Buenos Aires: Godot, 2019.

MARIO, Silvia; PANTELIDES, Edith Alejandra. Estimación de la magnitud del aborto inducido en la Argentina, Notas de Población, Naciones Unidas Comisión Económica para América Latina y el Caribe (CEPAL), 2009.

MAFFÍA, Diana. Contra las dicotomías: Feminismo y Epistemología crítica. In: KOROL, Claudia (comp.). Feminismos populares, pedagogías y políticas. Buenos Aires: Editorial Chirimbote, 2016.

SEGATO, Rita. Contra-pedagogías de la crueldad. Buenos Aires: Prometeo, 2018.

VERÓN, Eliseo. La semiosis social. Fragmentos de una teoría de la discursividad. Barcelona: Gedisa, 2007.

ROCHA, M. I. B. da; ROSTAGNOL, S.; GUTIÉRREZ, M. A. Aborto y Parlamento: un estudio sobre Brasil, Uruguay y Argentina. R. Bras. Est. Pop., Rio de Janeiro, v. 26, n. 2, p. 219-236, jul./dez. 2009.

SAFFIOTI, Heleieth I.B. A mulher na sociedade de classes. São Paulo: Expressão Popular, 1997.

TABBUSH, Constanza; DÍAZ, María Constanza, TREBISACCE, Catalina; KELLER, Victoria. Matrimonio igualitario, identidad de género y disputas por el derecho al aborto en Argentina. La política sexual durante el kirchnerismo (109-142). In: ROSSI, Felicitas; TABBUSH, Constanza (Coord.). Género, sexualidad e izquierdas latinoamericanas. Buenos Aires: CLACSO, 2020. 